\title{
The Mediating Role of Management Accounting Information and Organizational Culture Between Organizational Learning and Performance
}

\author{
Nguyen Bich LIEN ${ }^{1}$, Pham Tra LAM ${ }^{2 *}$, and Luong Duc THUAN ${ }^{3}$ \\ 123 Department of Accounting Information Systems, School of Accounting, \\ University of Economics Ho Chi Minh city, Ho Chi Minh, Vietnam \\ ${ }^{*}$ Corresponding author: phamtralamais@ueh.edu.vn
}

\begin{abstract}
Research purpose

This study focuses on the mediating role of management accounting information (MAI) and organizational culture in the relationship between organizational learning $(O L)$ and organizational performance.

\section{Research motivation}

The relationship between $O L$ and organizational performance has been the subject of discussion in management literature. However, certain studies have found a directly significant link between OL and organization performance, whereas others have not. In addition, MAI that is created from accounting information systems as well as organizational culture have important impacts on the enterprise performance. In an emerging economy like Vietnam, there are not that many empirical studies that focusing on OL, MAI, organizational culture, and organization performance. From the needs to improve the organization performance and the lack of research regarding the correlation of these factors, more empirical studies should be conducted in different contexts.
\end{abstract}

\section{Research design, approach, and method}

This is a quantitative research, using a survey approach. Designed based on theoretical foundations, a questionnaire was then self-applied to 170 enterprises. The data set was analysed to test the path model through PLS technique.

\section{Main findings}

The findings confirmed that MAI and organizational culture represents complementary mediations for the effects of OL on organization performance. Overall organizational performance was significantly influenced by MAI $(\beta=0.360)$, organizational culture $(\beta=0.346)$, and $O L(\beta=0.221)$. All three factors together can explain 73.3 percent of the variance in organizational performance.

\section{Practical/managerial implications}

Findings can be useful for managers and practitioners of enterprises, encouraging further studies on the OL, MAI and organizational culture's role in assisting organization performance. The study has relevant implications for managers through the identification and analysis of the mediating role of MAI and organizational culture in the relationship between $O L$ and performance.

Keywords: Organizational Learning, Management Accounting Information, Organizational Culture, Performance.

\section{INTRODUCTION}

To cope with the rapid changes in business environment, continuous OL is essential to acquire and apply new knowledge in innovation. Several studies show that OL that is continuously supported by companies outperforms their counterparts (Beyene et al., 2016). Learning is an important vehicle of organizational competence that enables companies to successfully develop new products and modify existing processes effectively (Jerez-Gomez et al., 2017). OL is a dynamic process for creating, acquiring, and integrating knowledge and thus facilitating innovative performance (Jerez-Gomez et al., 2017).

The concept of OL has received considerable attention over the past few decades. With a multidisciplinary background, this concept has been widely applied and widely defined in the study of the processes of knowledge transfer (Nonaka, 1994), exploitation and discovery to adaptive capacity for OL (Chiva et al., 2007), research on communities of practice (Brown \& 
Duguid, 1991), research on power and political processes (Lawrence et al., 2005). While academic perspectives may be different, most definitions of OL emphasize the interaction between learning at the individual, group, and organizational levels (Di Milia $\&$ Birdi, 2010) and pay particular attention to the flow of knowledge sharing between different levels.

Given the importance of OL to stimulate innovation, several studies have investigated the determinants of OL and provided the core role of an innovation culture in organizations (Sanz-Valle et al., 2011). Based on contingency theory, OL brings about an open atmosphere in a company in which employees, as motivating of innovation, are expressed more creativity and thus give the company more opportunities to innovate (Matías-Reche et al., 2010).

From the literature review, we found that OL has a significant effect on firm performance (Patky, 2020; Bhaskar \& Mishra, 2017) that can be measured by profitability, or other financial benefits in knowledge management (Davenport et al., 1999). There is a positive relationship between OL and organizational performance, with non-financial outcomes being stronger than financial performance (Goh et al., 2012). Besides, OL is also correlated with MAI that is an outcome of accounting information systems (AIS), which help support management activities and decision-making processes (Gelinas et al., 2011). Based on the contingency approach, previous studies (e.g., Yadav, 1985; Blaylock \& Rees, 1985; Lederer \& Smith, 1989; Choe, 1998) have examined and found relevant types of information needed in diverse contexts, investigates the relationship between contextual variables and informational characteristics affecting firm performance. Choe (2004) investigated $\mathrm{OL}$ in relation to accounting and examined the relevant types of MAI required by advanced production technology to operational performance and improve performance from view of OL. Choe (2004) also showed that OL affects the relationship between MAI and organizational performance. In addition, empirical evidence from Cho (2007) demonstrated that OL does not affect employees' performance and their satisfaction with the implementation of new technology. Furthermore, MAI was also found to have a significant positive correlation with operational performance (Choe, 2004). Although, some research papers have certified that OL and accounting have a relationship, there is a little literature examining OL and MAI. This paper focuses on the relationship between OL, MAI and organization performance.

Previous studies showed that organizational culture can promote innovation, as well as firm performance, or it can be an obstacle for both, depending on the values driven by the organizational culture (Naranjo-Valencia et al., 2015). Companies need to positively perceive organizational culture characteristics to get the best results from the use of quality techniques for superior performance (Gambi et al., 2015).
OL is facing enormous challenges with the rapid development of the knowledge society. Therefore, there is a need to revisit traditional learning models to strengthen the practices of collective learning. Current studies (Sorakraikitikul \& Siengthai, 2014; Cerne et al, 2012) have highlighted the importance of developing an organizational learning culture for employees and organizations. Such a culture needs to be able to facilitate knowledge transfer processes. Indeed, the ultimate goal of learning organization research is to facilitate the development of an effective OL which in turn enhances firm performance (Vaill, 2007) and thus research to improving $\mathrm{OL}$ is always the key to achieving this goal. Based on the theoretical and practical significance of OL, OL has a certain role to play in firm performance and organizational culture.

Because of the important role of OL, MAI and organizational culture in the enterprise's success, studying on this topic is significant, especially in an emerging market like Vietnam. This study investigated the how MAI and organizational culture relates to the relationship of OL and organization performance.

\section{LITERATURE REVIEW}

\subsection{Organizational learning}

Learning is the acquisition of new knowledge to apply in making decisions or influencing others (Miller, 1996). There has been a variety of definitions of OL. In general, OL means the process of improving actions through better knowledge and understanding (Fiol \& Lyles, 1985); through its processing of information, the range of its potential behaviours is changed (Huber, 1991). It is a process of detecting and correcting the error (Argyris, 1977), occurring through shared insights, knowledge, and mental models, and building past knowledge and experience on memory (Stata, 1989).

OL takes place when disjunctions, discrepancies, surprises, or challenges act as triggers of response and OL (Marsick \& Watkins, 2003). These triggers for fundamental changes at the organizational level, such as in their vision, ideology, and structure (Meyer, 1982), or a new regulation, a new competitor, market downturns, new technology, customer dissatisfaction or new demands, some other change (Marsick \& Watkins, 2003). These changes encourage the application of new knowledge among organizational members to solve the issues or problems, therefore helping individuals play more active roles in knowledge creation (Lee \& Choi, 2003). The process of interpersonal interaction is also a process of interaction and knowledge accumulation, so knowledge is spread and transferred from one working department to another throughout the organization, from individual to group level, and vice versa (Gold et al., 2001). This whole process of interaction and knowledge accumulation is OL. According to (Miller, 1996), OL could be evoked by six common traits, which include analytic, synthetic, experimental, interactive, structural, and institutional learning. 
Our paper uses the concept and OL dimensions of Marsick and Watkins (2003) to define OL has seven dimensions because it can express OL as a process and result of interaction and knowledge accumulation. These are the seven dimensions of the learning organization (Marsick \& Watkins, 2003) include: "Create continuous learning opportunities; Promote inquiry and dialogue; Encourage collaboration and team learning; Create systems to capture and share learning; Empower people toward a collective vision; Connect the organization to its environment; Provide strategic leadership for learning."

\subsection{Organization Culture}

Most definitions are focused on culture as a critical aspect of the adaptation of social organizations and viewed culture as a system of "Socially transmitted behavior patterns that serve to relate human communities to their ecological settings" (Keesing, 1974).

The organization's culture is the elemental set of key values, beliefs, assumptions, and norms shared by employees (Denison \& Mishra 1995, Fey \& Denison 2003, Denison 2006). It is norms, values, behaviour patterns, rituals, traditions that surround us all and is the accumulated shared learning from shared history (Schein, 2010).

There are three formation levels of organizational culture including (1) Artifacts including visible organizational structures and processes or language, company's uniform; (2) Espoused Beliefs and Values that are communicated with strategies, goals, philosophies; and (3) Underlying Assumptions expressing by unconscious, taken-for-granted beliefs, perceptions, thoughts, and feelings (Schein, 2010).

Denison and Mishra (1995), Fey and Denison (2003) and Denison (2006) have focused specifically on those aspects of culture having the greatest impact on business performance. Those traits of organizational culture are categorized into four types including adaptability, consistency, involvement, and mission. Adaptability refers to the degree of ability to adapt to organizational behaviour, structures, and systems to survive when dealing with environmental changes. Consistency is the extent to which members keep beliefs, values, and expectations stably. Involvement is the level of participation by organization members in decision-making that will affect their work and that their work is directly related to the organization's goals. Mission refers to the existence of a shared organization's purpose. This paper uses concepts and measures of Denison and his colleagues' framework mentioned above because it can express core traits of organizational culture to characterize effective organizations as well as help to study as an integral part of the adaptation process of organizations (Denison \& Mishra, 1995; Denison, 2006).

\subsection{Management Accounting Information}

MAI is a product of the management of the accounting information system and assists managers in their planning, control, and evaluation of production activities. Management-wise, in general, MAI can be categorized into two types: planning and control information (PCI), and performance evaluation information. Financial information is usually used for plan and control purposes; however, both financial and non-financial are commonly used for evaluation purposes (Abernethy \& Brownell, 1997). This financial information consists of standard costing, budgeting, direct costing, variable costing, life-cycle costing, and long-range cost trends for the control and coordination of interrelated activities, generated by management accounting techniques such as traditional as well as ABC (Choe, 2004). The non-financial information provides additional information that explains and evaluates the organization's performance.

\subsection{Organization Performance}

The word performance is widely used in all fields of management. Organizational performance considers the degree to which an organization achieved its business objectives and is measured by different perspectives such as accounting, marketing, operations, or simply a result of a process, an activity depending on the purpose of management. This paper focuses on understanding changes in overall and operation perspectives of organizational performance caused by the impact of OL, MAI, and organizational culture. In this context of our paper, the term "firm performance" means overall organizational performance or firm-level performance (as the term by Chuang, 2013).

Firm performance describes the overall concept of organizational performance that is developed and validated by (Deshpandé et al., 1993, Drew, 1999), is confirmed by Lee and Choi (2003), and is used by Chuang et al. (2013). The firm performance shows overall changes in market share, profitability, growth rate, innovativeness, and successfulness in comparison with key competitors. This concept and measure can be visualized as a variation of the balanced scorecard method (Lee \& Choi, 2003). Operation perspectives of organizational performance focus on cost changes for research and development to create competitive advantages, that is confirmed and used by (Robins \& Wiersema 1995; Farjoun, 1998).

\section{THEORETICAL DEVELOPMENT AND} HYPOTHESES

\subsection{Organizational learning and organization performance}

To highlight the learning in an organizational context, Garvin (1993) described three overlapping stages OL. The first is cognitive, the second is behavioural because employees begin to internalize new insights and alter their behaviour, and the third is performance improvement in superior quality, better delivery, increased market share, or other tangible gains. Because cognitive and behavioural changes typically precede improvements in performance.

As mentioned in the concept of OL, knowledge is the result of OL. According to Huber (1991), this knowledge-creating process and development of organizational knowledge include four phases 
including the acquisition of information and existing knowledge from both the internal and external environment of the organization, its distribution within the company, its interpretation, and, finally, it's storing for future use in organizational memory

According to Fiol and Lyles (1985), Kloot (1997), and Choe (2004), the ultimate effect of valid OL increases or improves performance because, with resource-based view (RBV), knowledge is a distinctively unique and valuable resource that creates and sustains an organization's competitive advantage through exploiting and cultivating its capabilities to create knowledge (March, 1991; Choe, 2004; Little \& Ray, 2005; Dwivedi et al., 2011; Watkins \& Kim, 2018).

The strong and positive correlations between OL and perceived or actual organizational performance have been investigated by previous studies (Kumar, 2005; Kumar \& Idris, 2006; Rose et al., 2006; Davis \& Daley, 2008; Watkins et al., 2009; Awasthy \& Gupta, 2011; Noubar et al., 2011; Kim et al., 2017; Watkins \& Kim, 2018). Therefore, we make hypothesizes:

H1. OL has a positive impact on organization performance.

\subsection{Organizational learning and management accounting information}

For Bhatt and Grover (2005), Zhang and Tansuhaj (2007), the intensity of OL is considered as the organization's ability to capture, combine, and apply knowledge. Additionally, it is also an important antecedent to information requirements in defining an information system architecture. Furthermore, one conclusion of Choe (2004) is that OL must also be a significant guideline when designing information system components such as information content and presentation mode. From this argument, H2 is developed.

H2. OL has a positive association with MAI.

\subsection{Management accounting information and organization performance}

MAI is important and necessary for preparing plans, schedules, forecasts, rules, policies, and procedures. MAI also conveys the strategy and mission throughout the entire company in the process of planning, controlling, or evaluating information shortage that causes many problems in the manufacturing process (Choe, 2004). Accounting information plays a critical role in creating new knowledge and updating the organization's shared mental models (Lee \& Choi, 2003; Choe, 2004).

From the viewpoint of the RBV, MAI also is a valuable and intangible resource that sustains an organization's competitive advantage. Likewise, the result of prior research pieces, the mediating role of MAI in the relationship between OL and organization performance is pointed out. From these arguments, hypothesis $\mathrm{H} 3$ is developed:

H3. MAI has an impact on organization performance.

\subsection{Organizational learning and organizational culture}

Organizational learning knowledge is cited as a precursor to innovation. (Sanz-Valle et al., 2011). These innovation and new mechanisms have been absorbed in the learning process can be one of the abundant reasons for changing organizational culture (Schein, 2010). Furthermore, Bandura's social cognitive learning theory also explains that cognitive learning guides and leads to change human behaviour, which is a part of organizational culture (Nabavi, 2012). A study by Corfield and Paton (2016) proved that knowledge and knowledge management impact culture. From these arguments above, a hypothesis is developed.
H4. organizational culture

\subsection{Organizational culture and organization performance}

As cited from previous research papers, organizational culture gives birth to the relationship between employee motivation and job satisfaction to achieve organizational goals (Roodt et al., 2002). Organizational culture creates employee's motivation through five sources proposed by (Kanter,1989), that is mission (inspiring employees to believe in the importance of their work), agenda control (enabling employees to control their careers), a share of value creation (rewarding employees for successful efforts), learning (providing learning opportunities) and reputation (giving employees opportunities to get a name for themselves) (Ogbonna and Harris 2000). Staff's motivation and job satisfaction increase the willingness of the workers to work, thus increasing the efficiency and effectiveness of the organization (Roodt et al., 2002). Furthermore, organizational culture has been shaped and affected by the organization's leaders; and the Leaders Embed and Transmit Culture to govern the organization (Schein, 2010). Therefore, organizational culture affects organizational performance.

From the culture traits perspective, the concepts of traits were developed through a series of qualitative and quantitative studies by many previous researchers (Denison, 2006) (e.g., Katzenbach \& Smith, 1993; Lawler, 1986; Spreitzer, 1995; 1996; Gordon \& DiTomaso, 1992; Martin, 1992; Schein, 1992; Treacy \& Wiersma, 1995) focusing on the cultural traits of organizations that appear to influence their performance and effectiveness. These studies of Denison also proved organizational culture affects the effectiveness of that organization.

From the literature and analysis above, the H5 is developed.

H5. Organizational culture has an impact on organization performance 


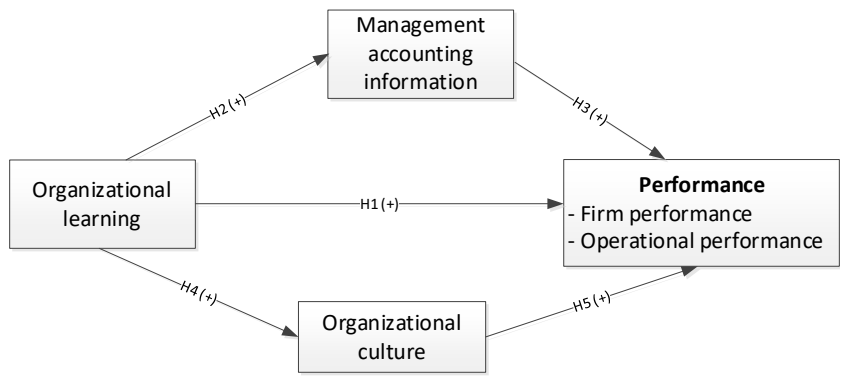

Fig. 1. Proposed research model

\section{METHODOLOGY}

\subsection{Instrument}

The tool of OL consists of 24 statements answered on a 7-point Likert scale, ranging from $1=$ 'Strongly Disagree' to 7 = 'Strongly Agree' (Marsick \& Watkins, 2003).

Previous research on performance effects of firms has mainly conceptualized firm performance and operationalized it by global output measures Chuang (2013). In this study, since OL represents a dramatic organizational change, we adopt an organizational change measure that operational and firm performance are developed and validated by Farjoun (1998); Robins and Wiersema (1995) and by Lee and Choi (2003) respectively (include three items for operational performance - OP and five items for firm performance - FP). These scales are used in Chuang (2013).

Literature review indicates that MAI scales are very diverse. In this research, planning control information (PCI), and non-financial performance information (NPI) are accepted from Choe (2004). PCI comprise kinds of cost planning and control information for the control and coordination of production activities (Scarbrough et al., 1991) that is measured using seven items (McNair, 1990; Scarbroug et al., 1991; Chenhall \& LangfieldSmith, 1998). NPI refers to the nonmonetary and qualitative measures like customer satisfaction, product quality, and cooperation (Bledsoe \& Ingram, 1997; Harrison \& Poole, 1997) and is measured by thirteen items (Perera et al., 1997).

Organizational culture (OCU) was operationalized based on the works of Denison and Mishra (1995) using eight statements that is a multidimensional construct comprising involvement (INV), consistency $(\mathrm{CO})$, adaptability (AD), and mission (MI).

\subsection{Sampling}

The companies selected for the survey of this study have a variety of number of employees. The final detailed questionnaire and a cover letter covering all the research-related issues that needed to be done were sent out to the companies in Vietnam. The questionnaire was submitted by online survey methods. Demographic information

The participants were asked to provide individual demographics including their age, gender, education, organizational role, and technology and job experience. In addition, respondents' organisational demographics comprising industry sector and organisation size (employment and capital status).
Since respondents are employees, middle managers, and senior managers, their experience and expertise in businesses operating in Vietnam. With this approach, we have collected the necessary data from 170 firms (Table 1).

Table 1. Detailed statistics of research samples by individuals

\begin{tabular}{lcc}
\hline Characteristics & Frequencies & Percentage \\
\hline Position & & \\
Staff & 130 & $76.5 \%$ \\
Department manager & 32 & $18.8 \%$ \\
Senior management & 8 & $4.7 \%$ \\
\hline Gender & & \\
Female & 121 & $71.2 \%$ \\
Male & 49 & $28.8 \%$ \\
\hline Age & & \\
$<35$ & 127 & $74.7 \%$ \\
$35-45$ & 36 & $21.2 \%$ \\
$>45$ & 7 & $4.1 \%$ \\
\hline Qualification & & \\
Master & 29 & $17.1 \%$ \\
Bachelor & 91 & $53.5 \%$ \\
College & 50 & $29.4 \%$ \\
\hline Experience & & \\
$<5$ years & 114 & $67.1 \%$ \\
$5-10$ years & 41 & $24.1 \%$ \\
$10-20$ years & 12 & $7.1 \%$ \\
$>20$ years & 3 & $1.8 \%$ \\
\hline Using software & & \\
$<5$ years & 99 & $58.2 \%$ \\
$5-10$ years & 47 & $27.6 \%$ \\
$10-15$ years & 15 & $8.8 \%$ \\
$>15$ years & 9 & $5.3 \%$ \\
\hline
\end{tabular}

Among 170 individuals participating in the survey, there are 130 employees (76.5\%), 32 department managers $(18.8 \%)$ and 8 senior managers $(4.7 \%)$. Male is 49 people $(28.8 \%)$ and female is $121(71.2 \%)$. The highest percentage of respondents for people under 35 years old was $127(74.7 \%)$. Bachelor's degree is the highest proportion $(53.5 \%)$, followed by college (29.4\%) and master's degree at $17.1 \%$. With $67.1 \%$ being the highest percentage of employees with less than 5 years of working experience and 5 to 10 years of working experience accounting for $24.1 \%$. These individuals have been working in enterprises in many different fields out of 170 surveyed enterprises, the highest proportion is the service area with $37.3 \%$, the second is the production and trading sector with the same of $26.5 \%$, and the third is other sectors, accounting for $9.8 \%$. There are also differences in firm size in the sample, with a major focus on large firms with more than $30 \%$ and small businesses with around $40 \%$ (Table 2). The number of enterprises using accounting software accounted for $88.2 \%$ and $11.8 \%$ of enterprises used the ERP system.

Table 2. Detailed statistics of research samples by enterprises 


\begin{tabular}{lcl}
\hline Characteristics & Frequencies & Percentage \\
\hline Business type & & \\
Service & 76 & 37.3 \\
Production & 54 & 26.5 \\
Trading & 54 & 26.5 \\
Others & 20 & 9.8 \\
Number of employees & & \\
$<=10$ people & 15 & 8.8 \\
$>10$ and $<=50$ people & 64 & 37.6 \\
$>50$ and $<=100$ people & 17 & 10 \\
$>100$ people & 74 & 43.5 \\
Total capital & & \\
$<=3$ billion VNĐ & 31 & 18.2 \\
$>3$ and $<=50$ billion VNĐ & 74 & 43.5 \\
$>50$ and $<=100$ billion VNĐ & 14 & 8.2 \\
$>100$ billion VNĐ & 51 & 30 \\
\hline$\quad$ DATA ANALYSIS AND RESULTS
\end{tabular}

\section{DATA ANALYSIS AND RESULTS}

\subsection{Pre-tests}

Nonresponse test

Since, data of this study is collected through online survey, nonresponse bias might be a problem. We use an independent samples t-test for examining nonresponse bias. Based on Armstrong and Overton (1977), survey responses are split into early and late respondents and analysed for differences in key demographic and study variables. Using SPSS 26.0, the findings indicate that nonresponse does not bias our findings because the $t$-test does not yield statistically significant mean differences between the groups.

Robustness test

The respondents who answered the independent variable also answered the dependent variable in a Table 3. Results of unobserved heterogeneity test cross-sectional manner, and our study is thus prone to common method bias. To investigate if potential threats of common method bias exist or not, we conduct three design procedures. First, we refined measure items of questionnaires based on pre-test feedback and guaranteeing respondent anonymity (Podsakoff et al., 2003). Second, this work also diagnoses a possible CMB issue with Harmon's singlefactor approach. An unrotated principal component analysis indicates that a common method variance was not a problem because several factors with eigenvalue greater than 1 were identified, which accounted for $79.968 \%$ of the total variance; and Factor 1 accounted for $47.546 \%$ of the variance. Final, according to Kock (2015), the VIF should be used to examine CMB S (Kock, 2015). The PLS results through SmartPLS 3.0 show that all VIF indexes are lower than the acceptable thresholds of 3.3 (Table 3). Therefore, in this paper, CMB is unlikely to threaten the validity of the findings. Testing the structural model estimate's robustness, FIMIX-PLS technique was applied to examine unobserved heterogeneity as proposed by (Hair Jr, Sarstedt et al. 2017). Running FIMIX-PLS dropped in the two segments solution as segment size of third segment solution is too small $(5.5 \%)$ which is lower than the threshold of a reasonable segment of $25 \%$. The results shown in Table 3 indicate that all criteria including $\mathrm{AIC}, \mathrm{AIC} 3, \mathrm{AIC} 4, \mathrm{BIC}$ and $\mathrm{CAIC}$ are highest at the first segment solution in comparison with the second segment solution. Overall, in combination these results indicates that heterogeneity was not prevalent in this research data.

\begin{tabular}{|c|c|c|c|c|c|}
\hline & Segment 1 & Segment 2 & Segment 3 & & \\
\hline AIC (Akaike's Information Criterion) & $2,362.723$ & $2,020.579$ & $1,924.368$ & & \\
\hline AIC3 (Modified AIC with Factor 3) & $2,391.723$ & $2,079.579$ & $2,013.368$ & & \\
\hline AIC4 (Modified AIC with Factor 4) & $2,420.723$ & $2,138.579$ & $2,102.368$ & & \\
\hline BIC (Bayesian Information Criteria) & $2,452.619$ & $2,203.472$ & $2,200.256$ & & \\
\hline CAIC (Consistent AIC) & $2,481.619$ & $2,262.472$ & $2,289.256$ & & \\
\hline HQ (Hannan Quinn Criterion) & $2,399.218$ & $2,094.827$ & $2,036.368$ & & \\
\hline MDL5 (Minimum Description Length with Factor 5) & $3,044.204$ & $3,407.040$ & $4,015.808$ & & \\
\hline LnL (LogLikelihood) & $-1,152.362$ & -951.290 & -873.184 & & \\
\hline EN (Entropy Statistic (Normed)) & & 0.870 & 0.853 & & \\
\hline NFI (Non-Fuzzy Index) & & 0.902 & 0.858 & & \\
\hline NEC (Normalized Entropy Criterion) & & 21.310 & 24.097 & & \\
\hline \multirow{5}{*}{$\begin{array}{l}\text { Nonlinear Effects test } \\
\text { In PLS-SEM, relationships between constructs can take } \\
\text { various forms such as linear relationships or nonlinear } \\
\text { relationships. Therefore, we investigated whether } \\
\text { nonlinear relationships occur or not in our data. The } \\
\text { analysis indicated that nonlinear effects did not exist in } \\
\text { our data since the quadratic effects of exogenous }\end{array}$} & \multicolumn{3}{|c|}{ MAI_quadratic -> PER } & 0.691 & 0.490 \\
\hline & \multicolumn{3}{|c|}{ OCU_quadratic -> PER } & 0.536 & 0.592 \\
\hline & \multicolumn{3}{|c|}{ OL_quadratic $1->$ MAI } & 0.296 & 0.767 \\
\hline & \multicolumn{3}{|c|}{ OL_quadratic $2->$ OCU } & 0.054 & 0.957 \\
\hline & \multicolumn{3}{|c|}{ OL_quadratic 3 -> PER } & 0.851 & 0.395 \\
\hline
\end{tabular}
our data since the quadratic effects of exogenous variables in the model did not significant (Hair et al., 2017) (Table 4).

Table 4. Results of Evaluation of Nonlinear Effects

T Statistics P Values

\subsection{Measurement model}

The results of descriptive statistics of variables show that mean of all constructs is from 4.549 to 5.335 and Std. Deviation fluctuations is $[1.144 ; 1.491]$ (Table 4). The reliability and validity of constructs in the 
measurement model are assessed by examining internal consistency reliability, convergent validity, and discriminant validity Hair et al. (2016). Two items are eliminated due to insufficient factor loadings or crossfactor loadings (OL1 and OL2).

Table 5 presents standardized loading and other metrics for the item measures, as well as reliability and validity measures. All items in the measurement model exhibited factor loadings ranging from 0.691 to 0.954 that are above the cut-off value of 0.6 and were thus considered acceptable for the remainder of the analysis (Hsu \& Chang, 2014).
All the constructs have a Cronbach's alpha over the cut-off 0.60 . In addition, the reliability metrics for all the first-order constructs, ranging from 0.878 to 0.968 , also exceeded the recommended threshold of 0.70 and were thus acceptable (Fornell \& Larcker, 1981).

The significance of t-statistic for each indicator's outer loading in PLS imply a good convergent validity in this research (Hair et al., 2016). Furthermore, the average variance extracted (AVE) showed that all AVE values exceeded the recommended threshold of 0.50 (Fornell \& Larcker, 1981), thus displaying sound convergent validity.

Table 5. Assessing the measurement model

\begin{tabular}{cccccc}
\hline Measures & Number of items & Loadings & Cronbach's alpha & Composite reliability & AVE \\
\hline OL & 24 & $0.691-0.804$ & 0.965 & 0.968 & 0.576 \\
INV & 2 & $0.929-0.934$ & 0.848 & 0.929 & 0.868 \\
CO & 2 & $0.924-0.934$ & 0.842 & 0.927 & 0.863 \\
AD & 2 & $0.932-0.937$ & 0.854 & 0.932 & 0.873 \\
MI & 2 & $0.950-0.954$ & 0.897 & 0.951 & 0.907 \\
PCI & 7 & $0.746-0.840$ & 0.822 & 0.878 & 0.550 \\
NPI & 13 & $0.742-0.870$ & 0.955 & 0.960 & 0.650 \\
FP & 5 & $0.907-0.918$ & 0.950 & 0.961 & 0.832 \\
OP & 3 & $0.859-0.913$ & 0.873 & 0.922 & 0.798 \\
\hline
\end{tabular}

Table 6 displays the discriminant validity of the measurements. For good discriminant validity, all Heterotrait-Monotrait Ratio (HTMT) of constructs are importantly smaller than 1 (Henseler, Hubona, \& Ray, 2016). Moreover, the square root of the AVE of a construct must be larger than that of the construct's correlations with the other constructs (Fornell \& Larcker, 1981). Final, cross loadings on corresponding constructs are higher than the cross-factor loadings. The data indicated that our constructs satisfied this criterion, thus confirming discriminant validity.

Table 6. Results of discriminant validity (HTMT)

\begin{tabular}{ccccccccccc}
\hline & Mean & $S D$ & $A D$ & $C O$ & $F P$ & $I N V$ & $M I$ & NPI & $O L$ & $O P$ \\
\hline CO & 4.789 & 1.436 & 0.700 & & & & & & & \\
FP & 4.681 & 1.491 & 0.726 & 0.782 & & & & & \\
INV & 4.945 & 1.441 & 0.716 & 0.846 & 0.653 & & & & & \\
MI & 5.335 & 1.327 & 0.645 & 0.812 & 0.683 & 0.799 & & & & \\
NPI & 4.933 & 1.353 & 0.677 & 0.746 & 0.728 & 0.730 & 0.720 & & & \\
OL & 4.764 & 1.35 & 0.684 & 0.811 & 0.753 & 0.718 & 0.703 & 0.758 & & \\
OP & 4.569 & 1.144 & 0.739 & 0.796 & 0.793 & 0.707 & 0.657 & 0.779 & 0.777 & \\
PCI & 4.549 & 1.405 & 0.594 & 0.704 & 0.773 & 0.645 & 0.599 & 0.795 & 0.815 & 0.774 \\
\hline
\end{tabular}

\subsection{Structural model}

Data analysis was performed using partial least squares (PLS), a structural equation modelling technique that has become widely accepted in recent years due to its accuracy and utility (Chuang et al., 2013). This research used PLS with the bootstrapping resampling procedure to examine the path model. The examination of structural equation model (SEM) includes the coefficients of the causal relationships between constructs, which would validate the hypothesized effects, and the R square values, which indicate the amount of variance in dependent variables explained by their antecedents.

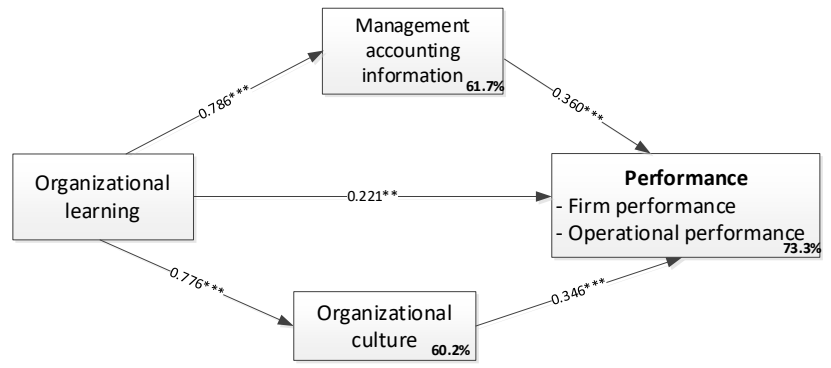

Fig. 2: Results of path analysis

Note: $* * * p<.001$.; ** $p<.01 ; * p<0.0$

Figure 2 presents the paths and their significance on the structural model. Overall organization performance was significantly influenced by MAI $(\beta=0.360, p<$ $0.001)$, organizational culture $(\beta=0.346, \mathrm{p}<0.001)$, 
and OL $(\beta=0.221, p<0.01)$. These factors explained $73.3 \%$ of the variance in organization performance, thereby demonstrating support for $\mathrm{H} 3, \mathrm{H} 5$, and $\mathrm{H} 1$. The path from OL to MAI $(\beta=0.786, p<0.001)$ is positive and significant, with $61.7 \%$ of the variance in MAI being explained. The finding provided empirical support for $\mathrm{H} 2$. In addition, H4 is also supported because OL has significant weights on organizational culture $(\beta=0.776, p<0.001)$ and $R$ square of organizational culture is $60.2 \%$. Results of the PLS analysis indicate the strong explanatory power of the model as coefficients of determination $\left(\mathrm{R}^{2}\right)$ of organization performance, MAI, and organizational culture.

\subsection{Mediated variables analysis}

Mediation analysis of MAI and organizational culture in the model, we tested the significance of the indirect effect and direct effect in two situations - exiting MAI and no exiting MAI as well as exiting organizational culture and no exiting organizational culture (Hair et al., 2017).

Following the results displayed in table 7, both MAI and organizational culture are partially mediating the relationship from OL to organization performance since both the direct and the indirect effects are significant. To further substantiate the type of partial mediation, we next compute the product of the direct and indirect effects. Because both the direct and indirect effects are positive, the sign of their product is also positive. Therefore, we conclude that MAI and organizational culture represents complementary mediations of the relationship from OL to organization performance.

Table 7. Testing the role of mediated variables

\begin{tabular}{lccccccc}
\hline Mediation model & \multicolumn{3}{c}{ Direct effects } & \multicolumn{4}{c}{ Indirect effects } \\
& $\begin{array}{c}\text { Path } \\
\text { Coefficient }\end{array}$ & $\begin{array}{c}\text { Palues } \\
\text { OL } \rightarrow \text { MAI } \rightarrow \text { PER }\end{array}$ & Sig. & $\begin{array}{c}\text { Path } \\
\text { Coefficient }\end{array}$ & $\begin{array}{c}\text { P } \\
\text { Values }\end{array}$ & Sig. & Conclusion \\
\hline OL $\rightarrow$ OCU $\rightarrow$ BI & 0.774 & 0.000 & Yes & 0.380 & 0.000 & Yes & $\begin{array}{c}\text { Partial mediation } \\
\text { (Complementary) } \\
\text { Partial mediation } \\
\text { (Complementary) }\end{array}$ \\
\hline
\end{tabular}




\section{Post-hoc analyses}

This study run several additional tests to examine our data sets. First, we examine effect sizes $\left(\mathrm{f}^{2}\right)$ that measures the contribution of an exogenous construct to the $\mathrm{R}^{2}$ value of an endogenous latent variable (Hair et al., 2017). The threshold values of small, medium, and large effect sizes are $0.02,0.15$, and 0.35 , respectively (Chin, 1998). While there is a medium effect of organizational culture to organization performance, MAI and OL have small effect sizes (Table 8). The high effects of OL to MAI and organizational culture are confirmed in this study.

Second, it values the predictive related matter of the path model by $\mathrm{Q}^{2}$ values. All $\mathrm{Q}^{2}$ values are considerably above zero with values for organization performance, MAI, and organizational culture are $0.484,0.325$, and 0.359 , respectively. Therefore, it provides support for the model's predictive relevance regarding the endogenous latent variables (Hair et al., 2016).

Table 8. Effect size and variance inflation measures for the structural models

\begin{tabular}{lrrrrrr}
\hline & \multicolumn{3}{c}{ Effect size } & \multicolumn{3}{c}{ VIF } \\
& PER & MAI & OCU & PER & MAI & OCU \\
\hline OL & 0.019 & 1.614 & 1.551 & 3.271 & 1.000 & 1.000 \\
MAI & 0.056 & & & 3.198 & & \\
OCU & 0.146 & & & 3.067 & & \\
\hline
\end{tabular}

Third, we checked for multicollinearity through the VIF index. The value of Variance Inflation Factor (VIF) is used to measure and assess the degree of multicollinearity. The collinearity diagnostics given in table 6 shows that VIF for the independent variables is higher than 0.20 (lower than 5) guideline recommended by Hair et al. (2016) which further suggests that multicollinearity does not exist among the independent variables.

Final, the goodness-of-fit index (GoF) is used to investigate the quality of the whole model. This value is calculated by taking the geometric mean of AVE for latent variables and the average $\mathrm{R}^{2}$ for endogenous variables (Tenenhaus, Vinzi, Chatelin, \& Lauro, 2005). The GoF value is 0.7168 and exceeds the cut-off value of 0.36 for the large effect of $\mathrm{R}^{2}$ (Wetzels, OdekerkenSchröder, \& Van Oppen, 2009). In addition, the standardized root mean squared residual value (SRMR) is 0.077 lower than the exclusion threshold $(0.08)$. It supports that the proposed research model is highly relevant (Hair et al., 2016).

\section{DISCUSSION}

The purpose of this paper is to develop a path model for validating the mediating roles of MAI and organizational culture in the relationship between $\mathrm{OL}$ and organization performance. According to the findings, MAI and organization performance partially mediate the relationship between OL and organization performance. These findings are entirely consistent with previous research. According to the findings, OL has a positive impact on both MAI (as determined by Choe (2004)) and organization performance (comparable to the study results of Goh \& Ryan, 2002; Watkins \& Kim, 2018). This is similar to previous discoveries in that, according to RBV, knowledge reaped and obtained by $\mathrm{OL}$ is a uniquely valuable resource for creating and sustaining an organization's competitive advantage and improving organizational performance (Choe, 2004). Another aspect is that a large amount of diverse information about planning, future-oriented trends, and performance measurement must be produced in order to manage and govern an organization. Due to inefficient learning, a lack of information causes a variety of issues in the manufacturing process (Choe, 2004). As a result, a direct or indirect positive correlation between $\mathrm{OL}$ and enterprise performance is explicitly explained.

The impact of OL on organizational culture is consistent with the findings of Nabavi (2012), Nabavi (2013), and Corfield and Paton (2016). Bandura's social cognitive learning theory, which states that cognitive learning affects organizational culture by influencing employee behavior, can explain the outcome.

Most previous studies conclude that organizational culture has an impact on organization performance, which is consistent with the findings of our study. This can be explained by the fact that an organization's employees' motivation and leadership styles are two of many important intangible resources for the organization's effectiveness.

\subsection{Theoretical implications}

From the theoretical point of view, the research results certify a positive relationship between OL and MAI, organizational culture, and performance. In addition, the positive relationship between MAI and organizational culture on firm performance and operational performance also makes a certain theoretical contribution. This study also contributes to the theory by showing support for the importance of OL in creating better organizational performance, improving the quality of MAI, and promoting better performance and organizational culture.

\subsection{Practical implications}

From a practical review, the research findings provide insights to improve organizational performance by creating a positive learning and culture environment, as well as enhancing MAI. More specifically, it can be suggested that organizations should encourage collaboration and learning by linking different parts of the organization and by developing a strong organizational culture. This can help in delivering learning throughout the firm, thereby improving MAI and performance. As a result, best practices can be institutionalized, and they can be made available to all employees in the firm. In fact, the findings of this study can provide firms with a fresh perspective that the concept of organizational culture, OL needs to be 
accepted by employees to contribute to strong innovation from an enterprise's perspective.

\section{CONCLUSION}

This study contributes to the broader literature on learning and culture of organization as well as MAI systems (MIS). Based on the resource-based view (RBV), the contingency theory, and the OL perspective, we investigated how MAI and organizational culture relates to the linking of OL and organizational performance. Based on our analysis of empirical data sets, we suggest that MAI and organizational culture complementary mediates the influence of OL on organization performance. Our findings emphasize the need to apply OL, MAI and organizational culture to foster the performance of enterprises.

Similar to most empirical research, this study is not without limitations and further ideas for future research. First, the responses to this study were voluntary, and thus, inevitably subject to self-selection variance. We checked for this potential problem relating $\mathrm{CMB}$. The tests result that our data did not suffer from high common method variance. Second, this study is cross-sectional, which allows the elaboration of correlations between variables but lacks confidence in causality exploration. We suggest that future scholars should explore relationships among OL, MAI, organizational culture, and organization performance in a longitudinal design to yield a more lucid understanding.

\section{REFERENCES}

[1] Abernethy, M. A. and P. Brownell. (1997), "Management control systems in research and development organizations: the role of accounting, behavior and personnel controls", Accounting, Organizations and Society 22(34), 233-248

[2] Argyris, C. (1977), "Double loop learning in organizations", Harvard business review, 55(5), 115-125

[3] Armstrong, J. S., and Overton, T. S. (1977), "Estimating nonresponse bias in mail surveys", Journal of marketing research, 14(3), 396-402.

[4] Beyene, K. T., Shi, C. S., and Wu, W. W. (2016), "The impact of innovation strategy on organizational learning and innovation performance: do firm size and ownership type make a difference?", South African Journal of Industrial Engineering, 27(1), 125-136.

[5] Bhaskar, A. U., and Mishra, B. (2017), "Exploring relationship between learning organizations dimensions and organizational performance", International Journal of Emerging Markets.

[6] Bhatt, G. D., and Grover, V. (2005), "Types of information technology capabilities and their role in competitive advantage: An empirical study", Journal of management information systems, 22(2), 253-277.

[7] Blaylock, B. K., and Rees, L. P. (1984), "Cognitive style and the usefulness of information”, Decision Sciences, 15(1), 74-91.

[8] Brown, J. S., and Duguid, P. (1991), "Organizational learning and communities-ofpractice: Toward a unified view of working, learning, and innovation", Organization science, 2(1), 40-57.

[9] Černe, M., Jaklič, M., Škerlavaj, M., Aydinlik, A. Ü., and Polat, D. D. (2012), "Organizational learning culture and innovativeness in Turkish firms", Journal of management \& organization, 18(2), 193-219.

[10] Chin, W. W. (1998), "Commentary: Issues and opinion on structural equation modeling.Chiva, R., Alegre, J., and Lapiedra, R. (2007). Measuring organisational learning capability among the workforce", International Journal of Manpower.

[11] Cronbach, L. J. (1951), "Coefficient alpha and the internal structure of tests", psychometrika, 16(3), 297-334.

[12] Cho, V. (2007), "A study of the impact of organizational learning on information system effectiveness", International Journal of Business and Information, 2(1).

[13] Choe, J. M. (1998), "The effects of user participation on the design of accounting information systems", Information \& Management, 34(3), 185-198.

[14] Choe, J. M. (2004), "Impact of management accounting information and AMT on organizational performance", Journal of Information Technology, 19(3), 203-214.

[15] Choe, J. M. (2004), "The relationships among management accounting information, organizational learning and production performance", The Journal of Strategic Information Systems, 13(1), 61-85.

[16] Chuang, S. H., Liao, C., and Lin, S. (2013), "Determinants of knowledge management with information technology support impact on firm performance", Information Technology and Management, 14(3), 217-230.

[17] Chin, W. W. (1998), "Commentary: Issues and opinion on structural equation modeling".

[18] Davenport, S., Grimes, C., and Davies, J. (1999), "Collaboration and organisational learning: A study of a New Zealand collaborative research program", International Journal of Technology Management, 18(3-4), 173-187.

[19] Corfield, A., and Paton, R. (2016), "Investigating knowledge management: can KM really change organisational culture?", Journal of Knowledge Management.

[20] Denison, D. R. (2006), "Linking organizational culture and Business 
Performance: A Brief overview", Assessment, Evaluation, Improvement Success through Corporate Culture, 14.

[21] Denison, D. R., and Mishra, A. K. (1995), "Toward a theory of organizational culture and effectiveness", Organization science, 6(2), 204-223.

[22] Deshpandé, R., Farley, J. U., and Webster Jr, F. E. (1993), "Corporate culture, customer orientation, and innovativeness in Japanese firms: a quadrad analysis", Journal of marketing, 57(1), 23-37.

[23] Di Milia, L., and Birdi, K. (2010), "The relationship between multiple levels of learning practices and objective and subjective organizational financial performance", Journal of Organizational Behavior, 31(4), 481-498.

[24] Drew, S. (1999), "Building knowledge management into strategy: making sense of a new perspective", Long range planning, 32(1), $130-136$

[25] Dwivedi, Y. K., Wade, M. R., and Schneberger, S. L. (Eds.). (2011), "Information systems theory: Explaining and predicting our digital society (Vol. 1)", Springer Science and Business Media.

[26] Farjoun, M. (1998), "The independent and joint effects of the skill and physical bases of relatedness in diversification", Strategic Management Journal, 19(7), 611-630.

[27] Fey, C. F., and Denison, D. R. (2003), "Organizational culture and effectiveness: Can American theory be applied in Russia?", Organization science, 14(6), 686706.

[28] Fornell, C., and Larcker, D. F. (1981), "Structural equation models with unobservable variables and measurement error: Algebra and statistics".

[29] Fiol, C. M., and Lyles, M. A. (1985). Organizational learning. Academy of management review, 10(4), 803-813.

[30] Gambi, L. D. N., Boer, H., Gerolamo, M. C., Jørgensen, F., and Carpinetti, L. C. R. (2015), "The relationship between organizational culture and quality techniques, and its impact on operational performance", International Journal of Operations \& Production Management.

[31] Garvin, D. A. (1993), "Building a learning organization", Harvard Business Review, 71 (4).

[32] Gelinas, U. J., Dull, R. B., and Wheeler, P. (2014), Accounting information systems, Cengage learning.

[33] Goh, S. C., Elliott, C., and Quon, T. K. (2012), "The relationship between learning capability and organizational performance: A metaanalytic examination", The learning organization.
[34] Hair Jr, J. F., Hult, G. T. M., Ringle, C., and Sarstedt, M. (2016), A primer on partial least squares structural equation modeling (PLSSEM,. Sage publications.

[35] Hair Jr, J. F., Sarstedt, M., Ringle, C. M., and Gudergan, S. P. (2017), Advanced issues in partial least squares structural equation modeling, Sage publications.

[36] Hair, J. F., Sarstedt, M., Pieper, T. M., and Ringle, C. M. (2012), "The use of partial least squares structural equation modeling in strategic management research: a review of past practices and recommendations for future applications", Long range planning, 45(5-6), 320-340.

[37] Hair Jr, J. F., Sarstedt, M., Hopkins, L., and Kuppelwieser, V. G. (2014), "Partial least squares structural equation modeling (PLSSEM): An emerging tool in business research", European business review.

[38] Henseler, J., Hubona, G., and Ray, P. A. (2016), "Using PLS path modeling in new technology research: updated guidelines", Industrial management \& data systems.

[39] Huber, G. P. (1991), "Organizational learning: The contributing processes and the literatures", Organization science, 2(1), 88115.

[40] Jerez-Gómez, P., Céspedes-Lorente, J., and Pérez-Valls, M. (2019), "Do high-performance human resource practices work? The mediating role of organizational learning capability", Journal of Management \& Organization, 25(2), 189-210.

[41] Kanter, R. M. (1989), "The new managerial work", Harvard business review 89(6), 85-92.

[42] Kloot, L. (1997), “Organizational learning and management control systems: responding to environmental Accounting Research, 8(1), 47-73.

[43] Keesing, R. M. (1974), "Theories of culture", Annual review of anthropology 3(1), 73-97.

[44] Kock, N. (2015), "Common method bias in PLS-SEM: A full collinearity assessment approach", International Journal of $e$ Collaboration (ijec), 11(4), 1-10.

[45] Lederer, A. L., and Smith Jr, G. L. (1988), "Individual differences and decision-making using various levels of aggregation of information", Journal of Management Information Systems, 5(3), 53-69.

[46] Lawrence, T. B., Mauws, M. K., Dyck, B., and Kleysen, R. F. (2005), "The politics of organizational learning: Integrating power into the 4I framework", Academy of management review, 30(1), 180-191.

[47] Lee, H., and Choi, B. (2003), "Knowledge management enablers, processes, and organizational performance: An integrative 
view and empirical examination", Journal of management information systems, 20(1), 179228.

[48] Little, S., and Ray, T. (Eds.). (2005), Managing knowledge: an essential reader, Sage.

[49] Malhotra, N. K., Kim, S. S., and Patil, A. (2006), "Common method variance in IS research: A comparison of alternative approaches and a reanalysis of past research", Management science, 52(12), 18651883.

[50] March, J. G. (1991), "Exploration and exploitation in organizational learning", Organization science, 2(1), 71-87.

[51] Marsick, V. J., and Watkins, K. E. (2003), "Demonstrating the value of an organization's learning culture: the dimensions of the learning organization questionnaire", Advances in developing human resources, 5(2), 132-151.

[52] Matías-Reche, F., García-Morales, V. J., and Martín-Tapia, I. (2010), "Staffing services quality and innovativeness in pharmaceutical companies", International Journal of Selection and Assessment, 18(3), 342-350.

[53] Miller, D. (1996), "A preliminary typology of organizational learning: Synthesizing the literature", Journal of management,22(3), 485-505.

[54] Nabavi, R. T. (2012), “Bandura's social learning theory \& social cognitive learning theory", Theory of Developmental Psychology, $1-24$.

[55] Naranjo-Valencia, J. C., Jiménez-Jiménez, D., and Sanz-Valle, R. (2016), "Studying the links between organizational culture, innovation, and performance in Spanish companies", Revista Latinoamericana de Psicología, 48(1), 30-41.

[56] Nonaka, I. (1994), "A dynamic theory of organizational knowledge creation", Organization science, 5(1), 14-37.

[57] Ogbonna, E., and Harris, L. C. (2000), "Leadership style, organizational culture and performance: empirical evidence from UK companies", international Journal of human resource management, 11(4), 766-788.

[58] Patky, J. (2020), "The influence of organizational learning on performance and innovation: a literature review", Journal of Workplace Learning.

[59] Podsakoff, P. M., and Organ, D. W. (1986), "Self-reports in organizational research: Problems and prospects", Journal of management, 12(4), 531-544.

[60] Robins, J., and Wiersema, M. F. (1995), “A resource-based approach to the multibusiness firm: Empirical analysis of portfolio interrelationships and corporate financial performance", Strategic

management

journal, 16(4), 277-299.

[61] Sanz-Valle, R., Naranjo-Valencia, J. C., Jiménez-Jiménez, D., and Perez-Caballero, L. (2011), "Linking organizational learning with technical innovation and organizational culture", Journal of knowledge management.

[62] Sharma, R., Yetton, P., and Crawford, J. (2009), "Estimating the effect of common method variance: The method-method pair technique with an illustration from TAM Research", Mis Quarterly, 473-490.

[63] Schein, E. H. (2010), Organizational culture and leadership, John Wiley \& Sons.

[64] Sorakraikitikul, M., and Siengthai, S. (2014), "Organizational learning culture and workplace spirituality: Is knowledge-sharing behaviour a missing link?", The Learning Organization.

[65] Stata, R. (1989), "Organizational learning-the key to management innovation", MIT Sloan Management Review 30(3), 63.

[66] Tenenhaus, M., Vinzi, V. E., Chatelin, Y. M., and Lauro, C. (2005), "PLS path modeling", Computational statistics \& data analysis, 48(1), 159-205.

[67] Watkins, K. E., and Kim, K. (2018), "Current status and promising directions for research on the learning organization", Human Resource Development Quarterly, 29(1), 15-29.

[68] Wetzels, M., Odekerken-Schröder, G., and Van Oppen, C. (2009), "Using PLS path modeling for assessing hierarchical construct models: Guidelines and empirical illustration", MIS quarterly, 177-195.

[69] Vaill, P. B. (2007), "Interpersonal Relations in Organizations and the Emergence of Wisdom", Handbook of organizational and managerial wisdom, 327.

[70] Yadav, S. B. (1985), "Classifying an organization to identify its information requirements: A comprehensive framework", Journal of Management Information Systems, 2(1), 39-60.

[71] Zhang, M., and Tansuhaj, P. S. (2007), "Organizational culture, information technology capability, and performance: the case of born global firms", Multinational Business Review. 